\title{
Androgen Receptor Status
}

National Cancer Institute

\section{Source}

National Cancer Institute. Androgen Receptor Status. NCI Thesaurus. Code C158502.

Refers to the presence or absence of androgen receptor molecules on the surface of a cells in a specimen. 